\title{
Simultaneous Removal of Binary Mixture of Cationic Dyes onto Bombax Buonopozense Bark: Plackett-Burman and Central Composite Design
}

\author{
Youness Achour ${ }^{1,2}$, Aziz El Kassimi 2, *(D), Imane Nadir ${ }^{2}$, Hicham Yazid ${ }^{2}$, Abderrafia Hafid ${ }^{1}$, Mostafa \\ Khouili ${ }^{1}$, Mamoune El Himri ${ }^{2}$, My Rachid Laamari ${ }^{2}$, Mohammadine El Haddad ${ }^{2}$, (ID \\ 1 Laboratoire de Chimie Organique et Analytique, Faculté des Sciences et Techniques, Université Sultan Moulay Slimane, \\ BP 523, 23000 Beni-Mellal, Maroc \\ 2 Laboratory of Analytical and Molecular Chemistry, Poly-disciplinary Faculty of Safi, Cadi Ayyad University, BP 4162, \\ 46000 Safi, Morocco \\ * Correspondence: youness.achour@gmail.com (Y.A.); azizelkassimi2012@gmail.com (A.E.K.); elhaddad71@gmail.com \\ (M.E.H.);
}

Received: 25.02.2021; Revised: 28.03.2021; Accepted: 2.04.2021; Published: 20.04.2021

\begin{abstract}
In this study, the retention of BB41 and SAF was studied using a PBD three-level screening plan, as the initial concentration of dyes, $\mathrm{BBP}$ mass, $\mathrm{pH}$, and temperature. Pareto analysis to select the $\mathrm{pH}$ and the adsorbent mass as influential factors to make a CCD optimization plan, the optimization has established a quadratic mathematical model for each dye. The binary system's common optimal conditions were selected to be a BBP mass of $0.46 \mathrm{~g} / \mathrm{l}$ and a $\mathrm{pH}$ of 8.54 . Under optimal conditions, the removal efficiency of BB41 and SAF is 83.76 and $73.23 \%$, respectively, with the desirability of 1.00 , which is confirmed by a later experiment. The equilibrium adsorption data of BB41 and SAF in the mixture are well explained by the Langmuir isotherm with an adsorption capacity of 75.18 and $80.64 \mathrm{mg} / \mathrm{g}$, respectively. A good fit of the experimental data according to the pseudo-second-order kinetic model, with a correlation coefficient R2>0.99. Finally, Bombax buonopozense (BBP) was characterized using FTIR, SEM and elemental analysis.
\end{abstract}

Keywords: wastewater treatment; optimization; liquid adsorption; kinetics; adsorption.

(C) 2021 by the authors. This article is an open-access article distributed under the terms and conditions of the Creative Commons Attribution (CC BY) license (https://creativecommons.org/licenses/by/4.0/).

\section{Introduction}

All over the last decades, and year after year, clean water increases the demand continuously [1]; with climate change and the large exploitation of water resources, this leads to a reduction in world reserves [2]. Whereas the enforcement of laws that protects the environment is very limited, and the increase in industrial units led to a worsening situation and the coming generation's future. Many products are rejected in the aquatic system that have an effective direct or indirect which will cause problems on human health [3], the fauna and the flora, among these toxic products we find the synthetic dyes.

The dyes are largely used in industrial applications such as the textile industry [4], paper, plastic, leather, food, and cosmetics, making them easy to be in the environment [5]. Because of their toxicity, carcinogenic effect, and mutagenic and teratogenic properties [6], they are the object of concern. Therefore, their elimination from industrial wastewater becomes an unavoidable necessity before being evacuated [7]. The removal efficiency of dyes from aqueous media is carried out by different techniques such as precipitation, coagulation, adsorption, ozonation, membrane filtration, and electrochemical techniques [8]. The adsorption technique is divided among other techniques to be the most efficient, cheapest, and easily operable [9]. The investigation of a new adsorbent that will be less expensive and have a high 
adsorption capacity is not as easy as it appears to improve adsorption removal efficiency. The use of wood derivatives shows an important effect on the removal efficiency of cationic dyes as well as the higher adsorption capacity [10], which led us to select the bark tree of the Bombax buonopozense from Cameron forests with an important presence of cellulose and the $\mathrm{OH}$ group that has a significant ability to adsorb.

There are many studies on the adsorption of cationic dyes in a single mode, but few have treated the mixture [11]. Among the problems encountered in the mixtures, the interactions of the studied dyes' peaks can lead to errors in the measures. The study of the factors relating to the adsorption processes requires a lot of time and energy because of the variation of the parameters one by one, making the optimization of the parameters quite difficult. Experimental design is a statistical technique that is generally used to optimize process factors [12], model and reduce the number of experiments performed in the study, and increase the system's efficiency at the lowest cost and minimize experiments' error [13]. In this work, we focused on the simultaneous adsorption study of the binary mixture of Basic blue 41 (BB41) and Safranin (SAF) using BBP as a new adsorbent. The initial concentration of dyes, $\mathrm{pH}$, the adsorbent mass and the temperature were studied by the Placket Burman design (PBD) as a screening plan; the selected factors that may have a significant effect on the binary adsorption system will be studied using a central composite design(CCD) for optimizing factors and modeling the system by a mathematical model. The adsorption mechanism was studied through the adsorption kinetics and the isotherms of the studied dyes in the binary and single systems.

\section{Materials and Methods}

\subsection{Adsorbent-adsorbate.}

The bark of the stem of Bombax buonopozense abbreviated as BBP was harvested from local trees in Nkolbisson (Cameroon's central region). Dried at room temperature and crushed in small pieces, then washed several times with bi-distilled water in a way to remove different residues and left in the oven at $80^{\circ} \mathrm{C}$ for 10 hours, powdered and stored in a glass bottle for ulterior uses. The BBP characterization as a new ecological adsorbent was achieved by SEM, elemental analysis, and FT-IR. FT-IR spectra (4000 - $400 \mathrm{~cm}^{-1}$ range) were recorded by a VERTEX 70 FT-IR spectrometer. Scanning Electron Microscopy (SEM) images were obtained with TESCAN VEGA 3 at a high voltage $20 \mathrm{kV}$.

The dyes used in this study are Safranin (SAF) and Basic Blue 41 (BB41); solutions were prepared by dissolving $100 \mathrm{mg}$ of the powder in $1 \mathrm{~L}$ of distilled water to concentrate 100 $\mathrm{mg} / \mathrm{L}$. Some properties of these two dyes are cited in Table 1.

Table 1. Some general properties of BB41 and SAF dyes.

\begin{tabular}{l|l|l} 
Dye & BB41 & SAF \\
\hline C.I.Name & Basic Blue 41 & Safranin \\
\hline Molecular Weight $(\mathrm{g} / \mathrm{mol})$ & $482.57 \mathrm{~g} / \mathrm{mol}$ & $350.84 \mathrm{~g} / \mathrm{mol}$ \\
\hline$\lambda_{\max }(\mathrm{nm})$ & 606 & 518 \\
\hline Molecular Formula & $\mathrm{C}_{20} \mathrm{H}_{26} \mathrm{~N}_{4} \mathrm{O}_{6} \mathrm{~S}_{2}$ & $\mathrm{C}_{20} \mathrm{H}_{19} \mathrm{ClN}_{4}$
\end{tabular}

Figure 1 shows the individual and binary spectra of BB41 and SAF dyes. It can be seen that there is no overlapped between spectra of the two studied dyes in the binary mixture. 


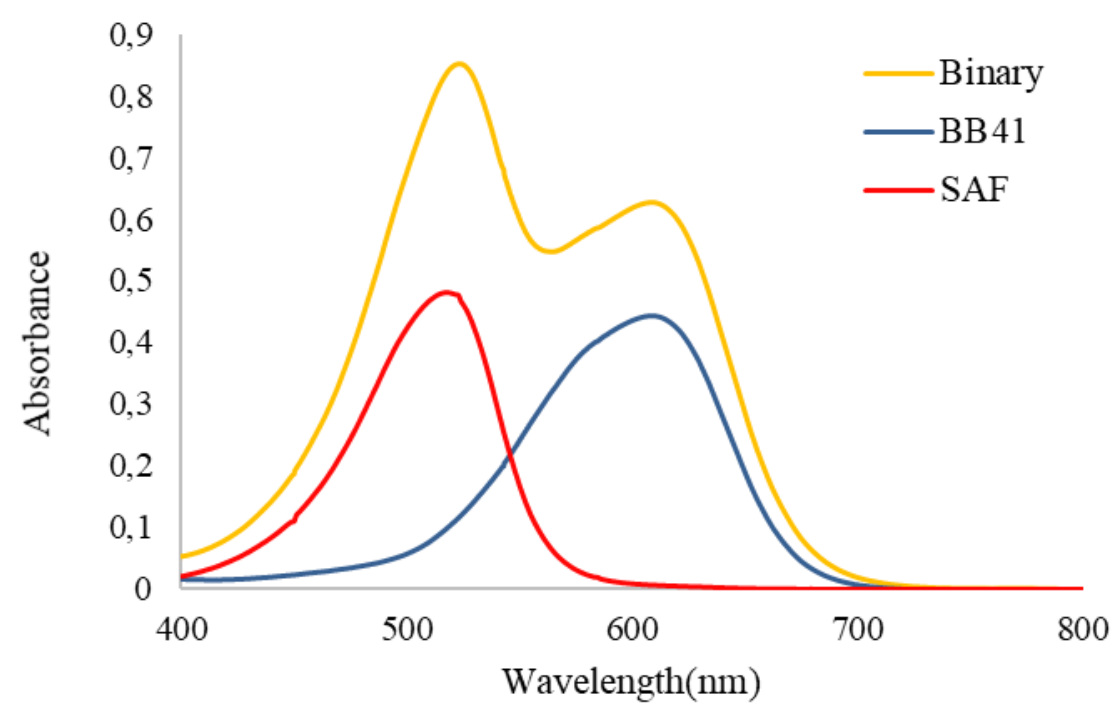

Figure 1. The individual spectra and the binary one of BB41 and SAF dyes.

\subsection{Adsorption process.}

The dye uptake experiments in a binary system were performed in batch mode, adding a known amount of BBP adsorbent to a solution of a known volume of BB41 and SAF at different concentrations. At the equilibrium, the solutions were centrifuged for two minutes at $1500 \mathrm{rpm}$, and the residual concentration of dyes was measured by a JENWAY 6300 spectrophotometer (UV/Visible). The adsorption capacity of dye at equilibrium $\mathrm{qe}_{\mathrm{e}}(\mathrm{mg} / \mathrm{g}$ ) was calculated via the following relation:

$$
q_{e}=\frac{C_{0}-C_{e}}{W} . V
$$

$\mathrm{C}_{\mathrm{e}}$ and $\mathrm{C}_{0}$ are the dye concentrations at equilibrium and the initial states of dye solution, respectively. Whereas $\mathrm{V}$ is the volume of the aqueous solution, and $\mathrm{W}$ is the mass of the used adsorbent [14]. The removal efficiency was calculated with the following relation:

$$
\text { Removal efficiency }(\%)=\frac{C_{0}-C_{e}}{C_{0}} .100
$$

$\mathrm{C}_{0}$ and $\mathrm{C}_{\mathrm{e}}$ are respectively the initial dye concentration and the concentration at equilibrium.

\subsection{Plackett-Burman design-screening.}

In the general case, it is necessary to use two steps in the multivariate optimization, which leads to a plan for screening the effects of the main factors [15, 16], then we optimize the conditions through a response surface. Plackett-Burman design is considered a very powerful technique for screening and gives a general idea about the effects of main parameters [17] to know the appropriate conditions to accelerate and maximize the removal efficiency of the binary mixture of cationic dyes. In this study, the removal efficiency of a binary mixture of BB41 and SAF was studied according to experimental results obtained from Plackett Burman design, where the adsorbent dosage, $\mathrm{pH}$, temperature, and the concentration of BB41 and SAF were selected as major factors that may have a significant effect on the removal efficiency of dyes. The Plackett-Burman plan allows studying $\mathrm{N}$ variables with two levels for each: -1 for the low level, +1 for the high level, and 0 for the central point (Table 2 ) where the five variables were studied in 15 experiments, including 3 repetition of the center point and two responses 
(Table 2). The experiments were fully randomized. The design of experiments was generated and evaluated by Minitab software version 17.1.0.

Table 2. PBD process variables and their ranges.

\begin{tabular}{l|l|l|l}
\multirow{2}{*}{ Factors } & Levels & \multicolumn{2}{l}{} \\
\cline { 2 - 4 } & Low(-1) & Center(0) & High(+1) \\
\hline $\mathrm{X}_{1}-$ Adsorbent dose $(\mathrm{g})$ & 0.2 & 0.4 & 0.6 \\
\hline $\mathrm{X}_{2}-\mathrm{pH}$ & 2 & 5.5 & 9 \\
\hline $\mathrm{X}_{3}-$ Temperature $\left({ }^{\circ} \mathrm{C}\right)$ & 25 & 40 & 55 \\
\hline $\mathrm{X}_{4}-\mathrm{BB} 41$ concentration(mg/L) & 10 & 15 & 20 \\
\hline $\mathrm{X}_{5}-\mathrm{SAF}$ concentration(mg/L) & 10 & 15 & 20
\end{tabular}

\subsection{Central composite design-optimization.}

The preliminary screening plan of the selected main factors using the Plackett-Burman design showed a significant effect of the adsorbent dose $\left(\mathrm{X}_{1}\right)$, and the $\mathrm{pH}\left(\mathrm{X}_{2}\right)$ on the removal efficiency of both dyes. The ranges of these two factors were set to establish a central composite design (CCD).

The Central Composite Design (CCD), using the Design-Expert software to estimate and optimize the most influential factors on dye adsorption and the effects of these factors' interactions on the dye removal efficiency in the aqueous mixture, was used [18, 19]. The CCD is composed of $2^{\mathrm{k}}$ of the factorial points and $2 \mathrm{k}$ experiments corresponding to the axial points with $\mathrm{k}$ is the number of factors studied, and $\mathrm{C}_{\mathrm{p}}$ is the number of the central point's [20], and the answers of the tests are quoted in Table 3. In the second part of this work, the effects of the main factors ( $\mathrm{pH}$ and adsorbent mass) were studied and their interactions. The relation between these two independent factors by adjusting a second-order polynomial equation allowed us to model the dye responses, which will be expressed as the following equation:

$$
Y=\beta_{0}+\sum_{j=1}^{k} \beta_{j} X_{i}+\sum_{j=1}^{k} \beta_{j j} X_{j}^{2}+\sum_{j=1}^{k} \sum_{i=1}^{k} \beta_{j i} X_{j} X_{i}
$$

Where $\mathrm{Y}$ is the predicted response (removal efficiency); $\mathrm{X}_{\mathrm{i}}, \mathrm{X}_{\mathrm{ij}}$ is the encoded parameters, and $\beta_{0}, \beta_{\mathrm{i}}, \beta_{\mathrm{ji}}$, and $\beta_{\mathrm{jj}}$ are the coefficients of the terms of the mathematical model [21]. It must be considered that the polynomial model is an estimate of the true functional relation.

\section{Results and Discussion}

\subsection{Characterization of BBP adsorbent.}

Analysis of the FT-IR spectrum of the new BBP adsorbent (Fig. 2) clearly shows the presence of C-O bending and alkoxy groups across the $1041 \mathrm{~cm}^{-1}$ band, while the 1430 and $1321 \mathrm{~cm}^{-1}$ bands indicate the presence of acrylic and aliphatic $\mathrm{O}-\mathrm{H}$ deformation in the plane, respectively. The $3427 \mathrm{~cm}^{-1}$ band is relative to the elongation of the $\mathrm{O}-\mathrm{H}$ and $\mathrm{N}-\mathrm{H}$ bond. The last band with a value of $1628 \mathrm{~cm}-1$ is relative to the elongation of $\mathrm{C}=\mathrm{O}$. Moreover, elemental analysis shows high percentages of Carbon (48.35\%), Oxygen (44.06\%) and Calcium (3.97\%) and low percentages of Potassium (0.55\%), Magnesium (0.42\%) and Sulphur $(0.18 \%)$. 


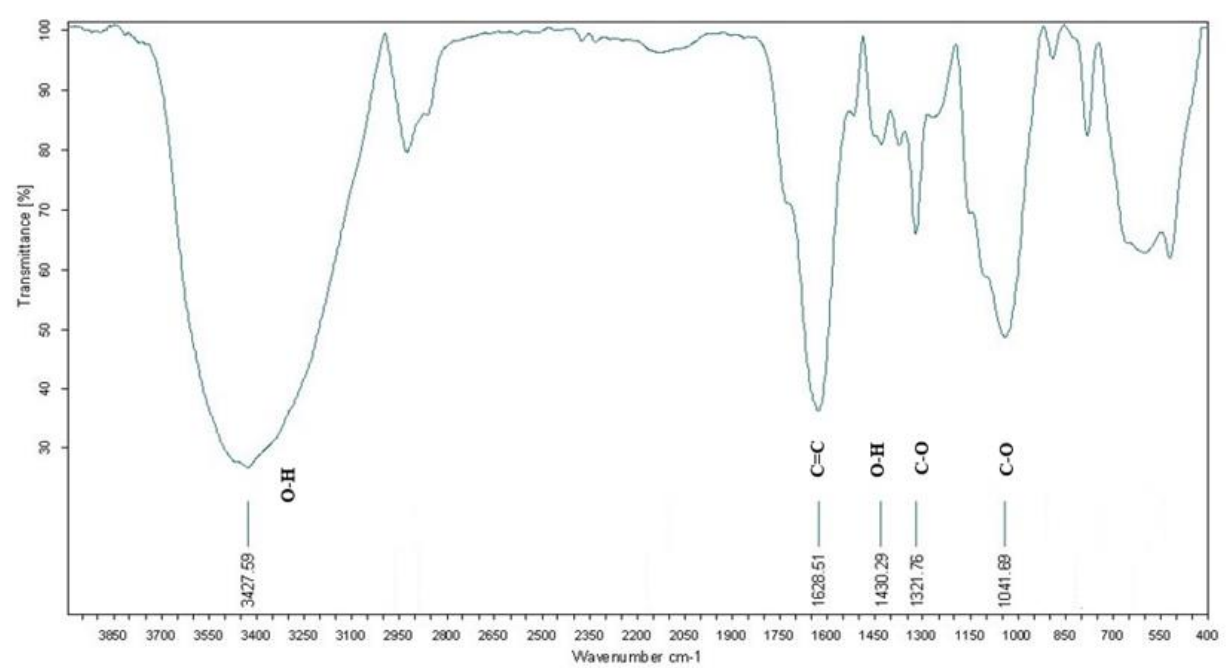

Figure 2. FT-IR spectra of BBP adsorbent.

SEM is the main tool capable of generating images of high-resolution sample surfaces, also characterizing the surface morphology and basic physical properties of the BBP surface as a new adsorbent. As shown in Figure 3, an important number of sites and the different sizes of spaces can be used specifically to adsorb dye molecules.

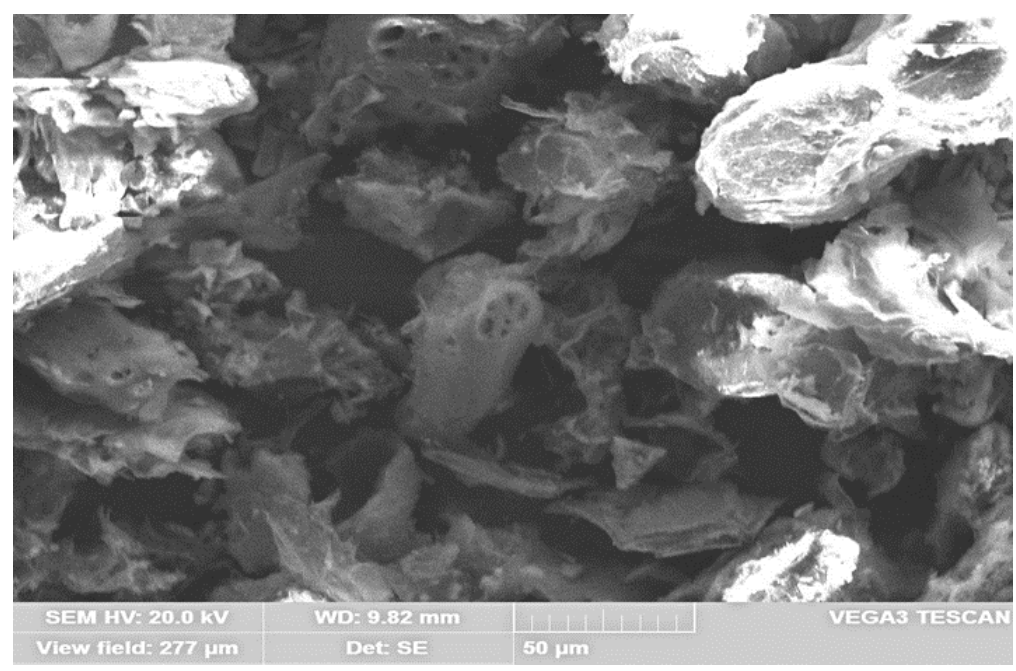

Figure 3. SEM image of BBP adsorbent.

\subsection{Significant effects of the main factors-PBD.}

Through the PBD, preliminary experiments by varying five factors with a $\mathrm{pH}$ (2.0 to 9.0), an adsorbent mass ( 0.01 to $0.03 \mathrm{~g}$ ), and a temperature ranging from ( 25 to $55^{\circ} \mathrm{C}$ ), and the concentration of SAF and BB41 ranges from $(10$ to $20 \mathrm{mg} / \mathrm{L})$ at two levels were examined with 15 experiments $(12+3$ central points). From these experiments, the results were analyzed using the Plackett-Burman design, which shows that the adsorbent mass (X1) and $\mathrm{pH}$ (X2) have the most significant effects. The analysis of the effects of the parameters is represented using the standardized principal effect Pareto plot $(\mathrm{P}=95 \%)$ Fig. 4, which shows the significant contribution of parameters $\mathrm{X}_{1}$ and $\mathrm{X}_{2}$ on the elimination of the dyes with $\mathrm{p}$ - values (p-value < 0.05). In the light of these screening results and to carry out an optimization, the other three non-significant variables were maintained at appropriate values. 
(a)

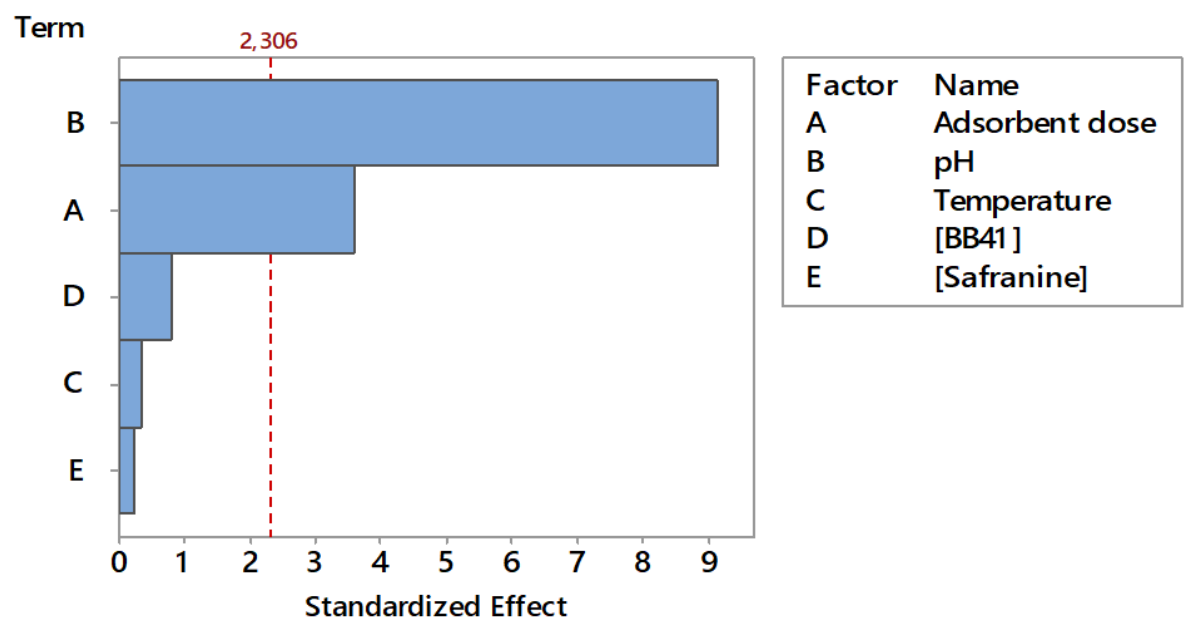

(b)

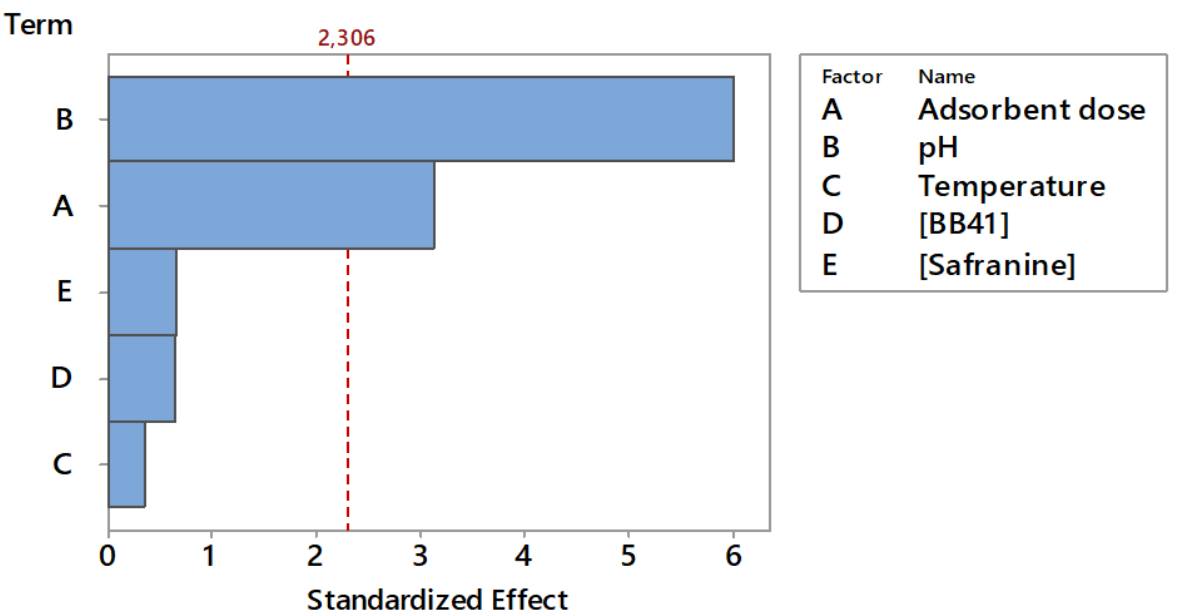

Figure 4. Pareto chart for BB41(a) and $\operatorname{SAF}(b)$.

\subsection{Response surface modeling(RSM).}

3.3.1. Mathematical modeling and analysis.

The CCD is presented in Table 3 with the experimental and predicted results of the two studied dyes using 13 experiments. To be able to select the correct mathematical model of the two responses among the different linear, interactive [22, 23], quadratic and cubic models. The experimental results were analyzed using two tests, the sequential sum of the model squares of the two responses (Table 4) and the summary statistics of the model (Table 5). The results of the two tests indicate that the linear and interactive models $(2 \mathrm{FI})$ have a low $\mathrm{R}^{2}$ regression coefficient, and also the $\mathrm{R}^{2}$ adjusted and predicted and higher $\mathrm{p}$-values compared to the quadratic model. The cubic model was found as an alias and is not recommended, so the quadratic model was chosen to describe the effects of the different terms of the adsorption system of BB41 and SAF in the aqueous mixture. The two quadratic polynomial models are obtained in terms of the coded factors of the two responses is given below:

$$
\begin{gathered}
\% B B 41=83.55+0.9653 * A+4.05 * B-0.5921 * A B+1.22 * A^{2}-0.879 * B^{2} \\
\% S A F=74.24+0.18 * A+6.57 * B-0.1326 * A B+1.49 * A^{2}-1.5 * B^{2}
\end{gathered}
$$

Where $\% \mathrm{BB} 41$ and \% SAF are the removal efficiency, $\mathrm{A}$ and $\mathrm{B}$ are the $\mathrm{pH}$ and the dose of adsorbent, respectively. 
Table 3. Central composite design matrix of two variables for simultaneous adsorption of dyes with experimental and predicted values for $\% \mathrm{R}$ of BB41 and SAF.

\begin{tabular}{c|c|c|c|c|c|c}
\multirow{2}{*}{ run } & \multirow{2}{*}{$\mathbf{p H}$} & \multirow{2}{*}{ Dose } & \multicolumn{4}{|c}{ Dye removal efficiency (\%) } \\
\cline { 4 - 7 } & & & \multicolumn{2}{|c}{ Experimental } & \multicolumn{3}{|c}{ Predicted } \\
\cline { 4 - 7 } & & & $\mathbf{B B 4 1}$ & $\mathbf{S A F}$ & $\mathbf{B B 4 1}$ & SAF \\
\hline 1 & 7.5 & 25 & 84.77 & 74.06 & 83.55 & 74.24 \\
\hline 2 & 6 & 30 & 86.55 & 80.17 & 87.57 & 80.76 \\
\hline 3 & 9.62 & 25 & 87.39 & 78.15 & 87.36 & 77.48 \\
\hline 4 & 7.5 & 17.92 & 74.94 & 60.07 & 76.06 & 61.94 \\
\hline 5 & 9 & 30 & 87.39 & 79.16 & 88.32 & 80.85 \\
\hline 6 & 7.5 & 25 & 82.92 & 73.28 & 83.55 & 74.24 \\
\hline 7 & 7.5 & 32.07 & 88.85 & 82.18 & 87.52 & 80.53 \\
\hline 8 & 7.5 & 25 & 82.37 & 74.91 & 83.55 & 74.24 \\
\hline 9 & 9 & 20 & 82.2 & 68.77 & 81.4 & 67.97 \\
\hline 10 & 5.37 & 25 & 84.8 & 76.09 & 84.63 & 76.97 \\
\hline 11 & 7.5 & 25 & 83.58 & 73.26 & 83.55 & 74.24 \\
\hline 12 & 7.5 & 25 & 84.11 & 75.72 & 83.55 & 74.24 \\
\hline 13 & 6 & 20 & 78.99 & 69.25 & 78.28 & 67.35
\end{tabular}

Table 4. Sequential model sum of squares for BB41 and SAF mixture.

\begin{tabular}{|c|c|c|c|c|c|c|c|}
\hline Dye & Source & Sum of squares & df & Mean square & F-value & p-value & Remarks \\
\hline \multirow[t]{7}{*}{ BB41 } & Mean & 91201.28 & 1 & 91201.28 & & & \\
\hline & linear & 138.84 & 2 & 69.42 & 23.86 & 0.0002 & \\
\hline & $2 \mathrm{FI}$ & 1.40 & 1 & 1.40 & 0.4558 & 0.5166 & \\
\hline & Quadratic & 18.02 & 2 & 9.01 & 6.52 & 0.0252 & Suggested \\
\hline & Cubic & 5.98 & 2 & 2.99 & 4.05 & 0.0902 & Aliased \\
\hline & Residual & 3.69 & 5 & 0.7389 & & & \\
\hline & Total & 91369.21 & 13 & 7028.40 & & & \\
\hline \multirow[t]{7}{*}{ SAF } & Mean & 71642.45 & 1 & 71642.45 & & & \\
\hline & linear & 345.89 & 2 & 172.94 & 31.21 & $<0.0001$ & \\
\hline & $2 \mathrm{FI}$ & 0.0703 & 1 & 0.0703 & 0.0114 & 0.9172 & \\
\hline & Quadratic & 35.90 & 2 & 17.95 & 6.46 & 0.0257 & Suggested \\
\hline & Cubic & 14.81 & 2 & 7.41 & 8.00 & 0.0277 & Aliased \\
\hline & Residual & 4.63 & 5 & 0.9258 & & & \\
\hline & Total & 72043.75 & 13 & 5541.83 & & & \\
\hline
\end{tabular}

Table 5. Model summary statistics for BB41 and SAF mixture.

\begin{tabular}{l|l|c|c|c|c|c|c}
\multirow{2}{*}{ Dye } & Source & Std.Dev. & $\mathbf{R}^{\mathbf{2}}$ & Adjusted $\mathbf{R}^{\mathbf{2}}$ & Predicted $\mathbf{R}^{\mathbf{2}}$ & PRESS & Remarks \\
\hline \multirow{3}{*}{ BB41 } & Linear & 1.71 & 0.8268 & 0.7921 & 0.6412 & 60.25 & \\
\cline { 2 - 8 } & 2FI & 1.75 & 0.8351 & 0.7802 & 0.5994 & 67.27 & \\
\cline { 2 - 8 } & Quadratic & 1.18 & 0.9424 & 0.9013 & 0.7096 & 48.77 & Suggested \\
\cline { 2 - 8 } & Cubic & 0.8596 & 0.9780 & 0.9472 & 0.9328 & 11.28 & Aliased \\
\hline \multirow{3}{*}{ SAF } & linear & 2.35 & 0.8619 & 0.8343 & 0.7069 & 117.62 & \\
\cline { 2 - 8 } & 2FI & 2.48 & 0.8621 & 0.8161 & 0.6446 & 142.64 & \\
\cline { 2 - 8 } & Quadratic & 1.67 & 0.9515 & 0.9169 & 0.7182 & 113.08 & Suggested \\
\cline { 2 - 7 } & Cubic & 0.9622 & 0.9885 & 0.9723 & 0.9680 & 12.85 & Aliased
\end{tabular}

3.3.2. Adequacy of the developed mathematical model.

The adequacy of the selected quadratic model is tested using the predicted versus actual plot (Fig.5a) and also a normal plot of the residuals (Fig.5b) in order to recognize the relationship between experimental values and that predicted ones and determine the ability of the selected model to predict the results of the removal efficiency of the studied mixture dyes. Fig 5 shows that the residuals via the two responses' prediction values are minimal, which is also confirmed by Table 3, which shows that there is good agreement between the experimental data and the predicted ones using the quadratic model [24]. 
(a1)

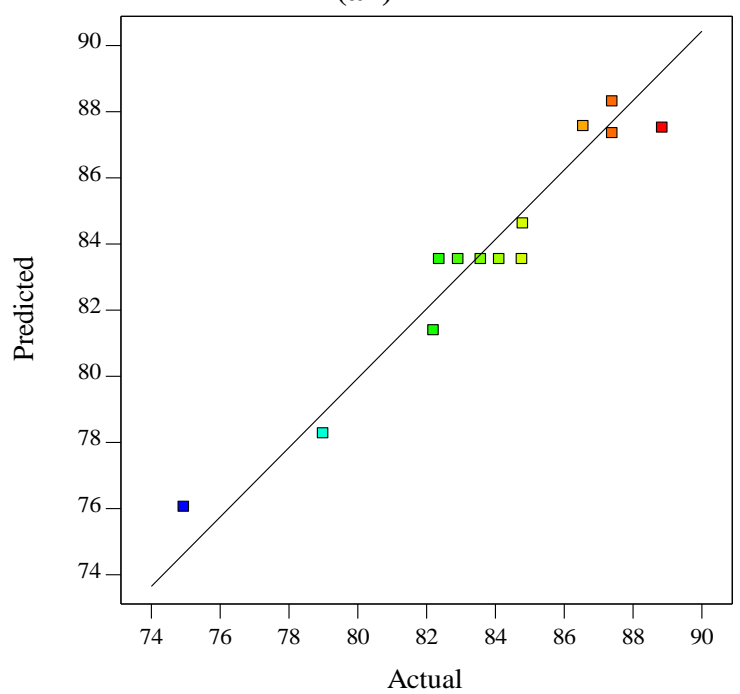

(b1)

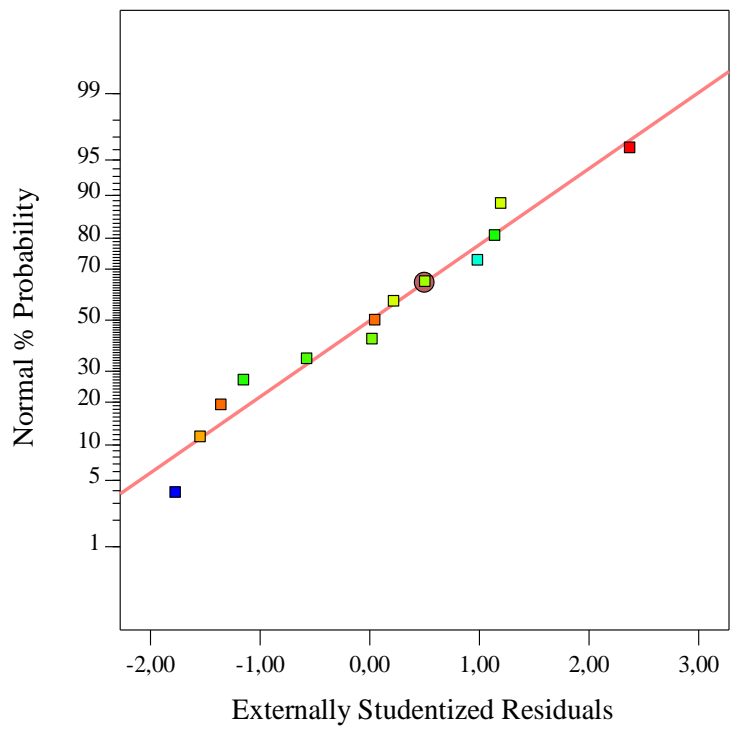

(a2)

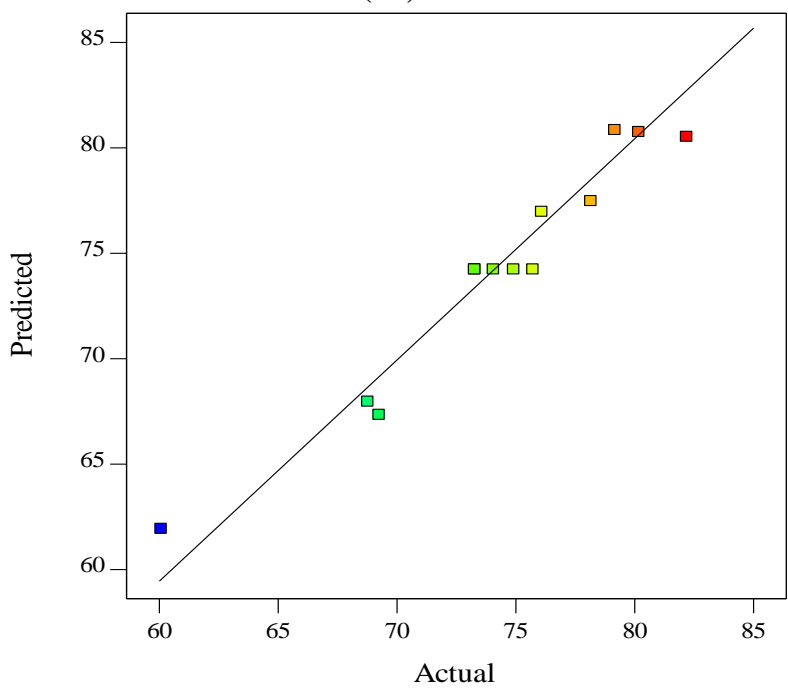

(b2)

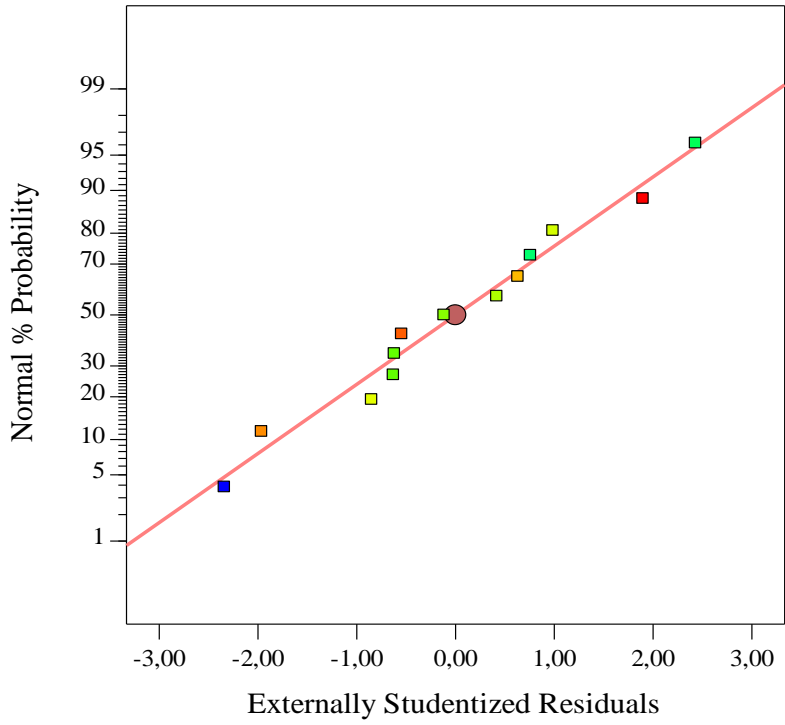

Figure 5. Model adequacy plots: actual vs. predicted plot for (a1) BB41 and (a2) SAF, a normal plot of residuals for (b1) BB41 and (b2) SAF.

Table 6. Analysis of variance (ANOVA).

\begin{tabular}{l|c|c|c|c|c|c|c|c|c}
\multirow{2}{*}{ Source } & \multicolumn{9}{|c}{ BB41 } \\
\cline { 2 - 11 } & df & $\begin{array}{c}\text { Sum of } \\
\text { Squares }\end{array}$ & $\begin{array}{c}\text { Mean } \\
\text { Square }\end{array}$ & F-value & p-value & $\begin{array}{c}\text { Sum of } \\
\text { Squares }\end{array}$ & $\begin{array}{c}\text { Mean } \\
\text { Square }\end{array}$ & F-value & p-value \\
\hline Model & 5 & 158.26 & 31.65 & 22.91 & 0.0003 & 381.86 & 76.37 & 27.49 & 0.0002 \\
\hline $\mathrm{A}-\mathrm{pH}$ & 1 & 7.45 & 7.45 & 5.39 & 0.0532 & 0.2591 & 0.2591 & 0.0933 & 0.7689 \\
\hline $\mathrm{B}-\mathrm{Dose}$ & 1 & 131.39 & 131.39 & 95.09 & $<0.0001$ & 345.63 & 345.63 & 124.43 & $<0.0001$ \\
\hline $\mathrm{AB}$ & 1 & 1.4 & 1.4 & 1.01 & 0.3473 & 0.0703 & 0.0703 & 0.0253 & 0.8781 \\
\hline $\mathrm{A}^{2}$ & 1 & 10.39 & 10.39 & 7.52 & 0.0288 & 15.48 & 15.48 & 5.57 & 0.0503 \\
\hline $\mathrm{B}^{2}$ & 1 & 5.37 & 5.37 & 3.89 & 0.0892 & 15.73 & 15.73 & 5.66 & 0.0489 \\
\hline $\mathrm{CV} \%$ & & 1.4 & & & & 2.25 & & & \\
\hline $\mathrm{R}^{2}$ & & 0.9424 & & & & 0.9515 & & & \\
\hline $\mathrm{AP}$ & & 15.34 & & & & 16.7 & & &
\end{tabular}

3.3.3. Analysis of variance(ANOVA).

ANOVA analyzed the statistical significance of the quadratic mathematical model already developed through the corresponding $\mathrm{F}$ and $\mathrm{p}$ values of the terms model of adsorption of the binary mixture (BB41+SAF) (Table 6). The high values of F-value and the low p-value of the two developed models confirm the significance of the quadratic models The quality of model regression was evaluated by the $\mathrm{R}^{2}$, adequate precision (AP), and CV\% 
$[27,28]$, which clearly shows that the differences between experimental and predicted values are so low and also confirms the reliability of the developed models. The AP measures the signal-to-noise ratio. A ratio greater than 4 is desirable. The ratio of 15.35 and 16.703 for BB41 and SAF, respectively, indicates an adequate signal. Those models are well used to navigate the design space.

\subsubsection{Response surface plots-3D.}

The three-dimensional graphs of the response surface of the interactions between studied factors influencing the removal efficiency of BB41 and SAF are presented in Fig. 6. These plots are obtained by a data interaction of two real factors, $\mathrm{pH}$ and adsorbent mass, at fixed and optimal values of other factors [29]. Fig.6a shows the interaction of the $\mathrm{pH}$ with the adsorbent mass for the case of BB41. The removal efficiency of BB41 increases with the increase of the adsorbent dose, which increases the active sites responsible for the adsorption. This shows a significant effect of the adsorbent mass on the removal efficiency of BB41, with no significant effect on $\mathrm{pH}$. On the other side, Fig.6b also shows the interaction effect of the $\mathrm{pH}$ and adsorbent mass on the removal efficiency of SAF; an increase in adsorbent mass directly influences the increase of the removal efficiency of SAF. We have seen that the adsorption efficiency of the two dyes of the mixture increases while increasing the mass of adsorbent, and the effect of the $\mathrm{pH}$ is not as important on the response.
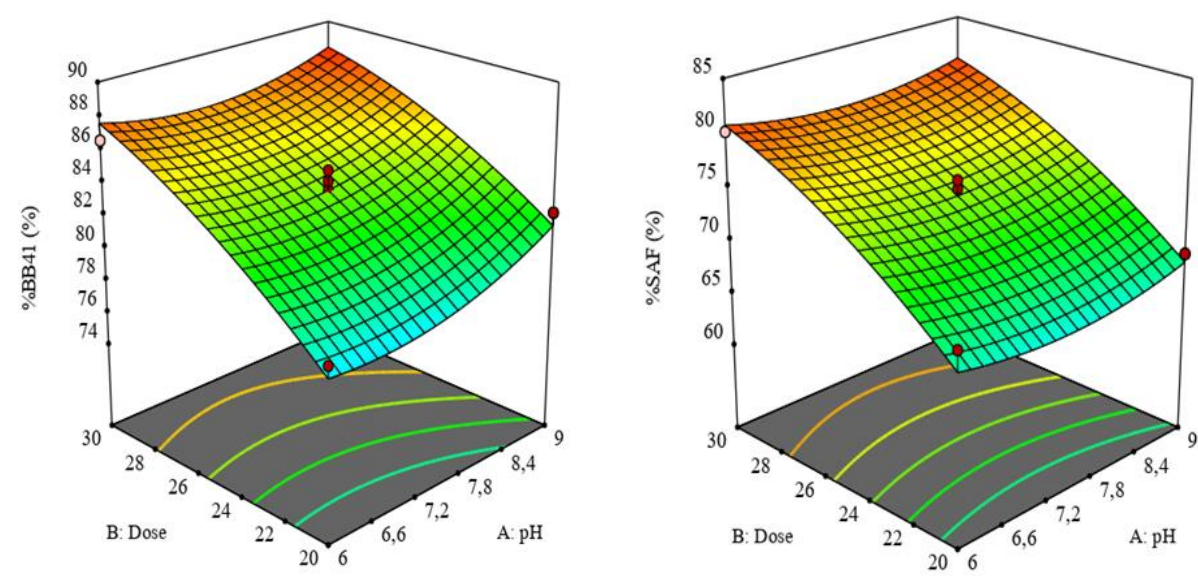

Figure 6. Response surface plots representing the effect of process variables on BB41 and SAF removal.

\subsubsection{Optimization and confirmation.}

Simultaneous optimization of BB41 and SAF responses was performed using a design expert to find optimal adsorption conditions for maximum retention of BB41 and SAF in a binary mixture. This method aims to evaluate a point that maximizes the desirability, and the common optimal conditions of the two dyes were as follows: a $\mathrm{pH}$ equal to 8.54 and an adsorbent mass equal to $0.46 \mathrm{~g}$, the temperature is set at $25^{\circ} \mathrm{C}$ and an initial concentration of dyes, which equals $20 \mathrm{mg} / \mathrm{L}$. Under the selected optimal conditions, the expected retention of BB41 and SAF was found to be $83.76 \%$ and $73.23 \%$, respectively, with desirability of 1.00 . The reproducible power of the optimal conditions to predict the optimal response values was tested. The values obtained by a real experiment gives $(83.07 \%$ and $73.5 \%)$ for BB41. SAF respectively, could validate the optimized conditions and the model. 


\subsection{Kinetics.}

The results gathered from the different kinetic experiments in single and binary systems were processed through first-order and second-order kinetic models. The values of $\mathrm{k} 1$ and qe were obtained from the linear adjustment of the points by the first-order model's trend curve with the correlation coefficients $\left(\mathrm{R}^{2}\right)$ of the different states of dyes are represented in Table 7 . The results of $\log (\mathrm{qe}-\mathrm{qt}$ ) versus time $(\mathrm{t})$ at various initial concentrations of dyes showed that the dye adsorption system did not follow the first-order kinetic model [30].

Also, the values of $\mathrm{R}^{2}$ may not be sufficiently high for different dye concentrations (from 10 to $50 \mathrm{mg} / \mathrm{L}$ ) in single and binary systems. Moreover, the calculated values $\left(\mathrm{q}_{\mathrm{e}}\right.$ ) of the kinetic model equation are very different from those measured experimentally. This confirms that the removal process does not follow the first-order model [31].

Using the second-order model, the curve that connects ( $\mathrm{t} / \mathrm{qt}$ ) and the time (t) should give a linear relationship to confirm whether the adsorption system follows a pseudo-secondorder model. For a linear graph of $(\mathrm{t} / \mathrm{qt})$ versus $(\mathrm{t})$ for all dyes, states are cited in Fig. 7. The values of $\mathrm{k}_{2}$, qe, and correlation coefficients $\left(\mathrm{R}^{2}\right)$ were calculated from the linear adjustment of the points by the second-order model's trend curve, as cited in Table 7. As shown in this table, the values calculated through the model are in good correlation to those measured experimentally. The correlation coefficients in the various states of the system are also strictly higher than 0.99. All this confirms that the adsorption system is well described by the pseudosecond-order model, which leads to an interpretation that this kinetic model gives an idea of the adsorption process that can most probably be controlled by the process of chimisorption [32].

Table 7. Kinetic data for BB41 and SAF in single and binary mixture.

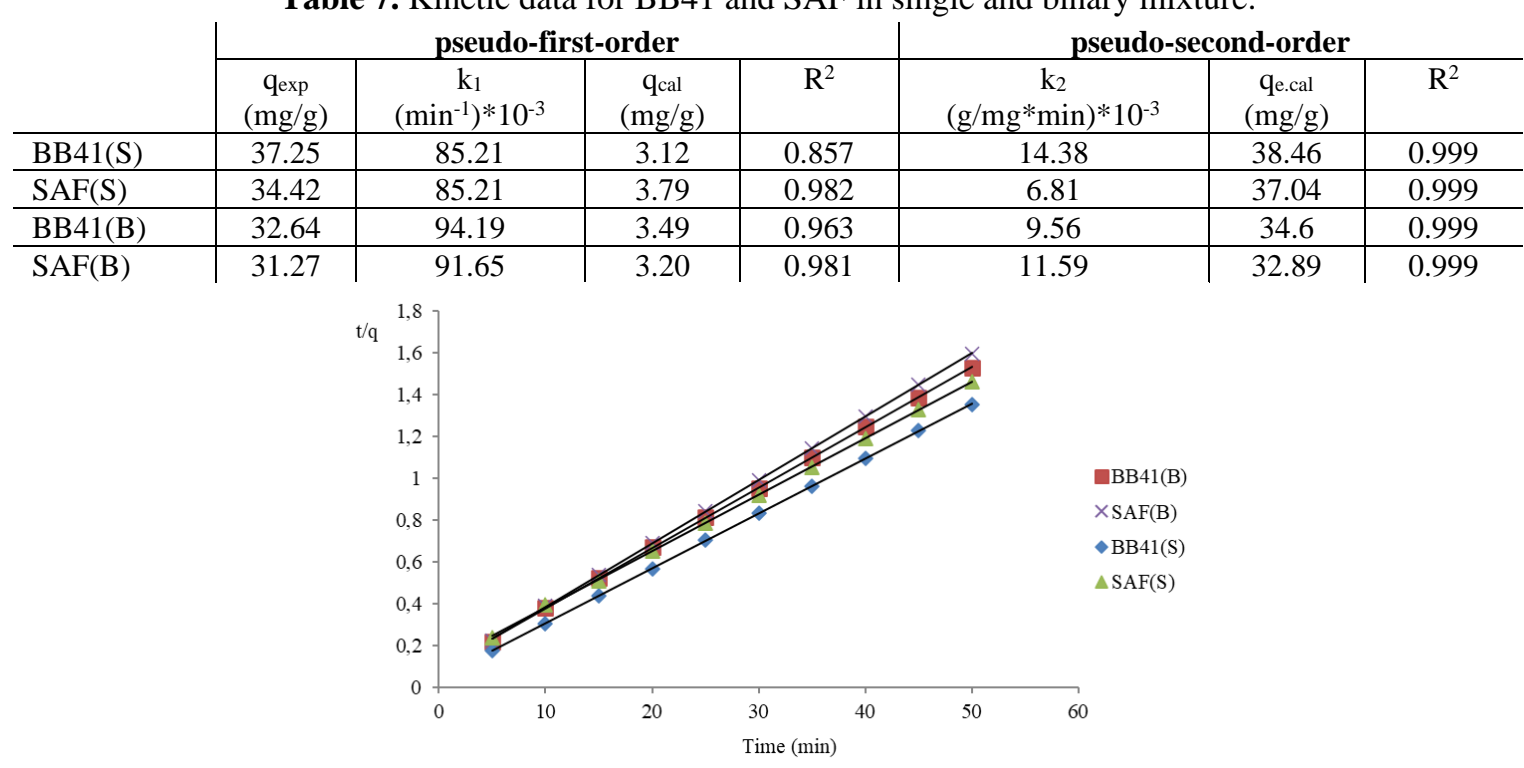

Figure 7. Plot of the equation of pseudo-second-order model for the single and binary system of BB41 and SAF dyes (T: $298 \mathrm{~K}$; pH: 8 ; BB41 and SAF concentrations: $20 \mathrm{mg} / \mathrm{L}$; BBP adsorbent: $25 \mathrm{mg}$ and V: $50 \mathrm{~mL}$ ).

\subsection{Adsorption isotherm.}

The Langmuir and Freundlich isotherms were called to understand the adsorption mechanism and have important information about the process. The Langmuir model's main objective is to assume that the dye molecules are attached to an adsorbent's solid surface forming a monolayer [33]. The plot of the curve $\left(\mathrm{C}_{\mathrm{e}} / \mathrm{q}_{\mathrm{e}}\right)$ versus $\mathrm{C}_{\mathrm{e}}$ should give a linear plot with 
an intercept point of $\left(1 / \mathrm{q}_{\mathrm{m}} \mathrm{K}_{\mathrm{L}}\right)$ and a slope of $\left(1 / \mathrm{q}_{\mathrm{m}}\right)$. Where Ce is the concentration of the dye at time of equilibrium in solution $(\mathrm{mg} / \mathrm{l}), \mathrm{q}_{\mathrm{e}}$ is the amount of dye adsorbed at time of equilibrium $(\mathrm{mg} / \mathrm{g}) ; \mathrm{K}_{\mathrm{L}}$ is the equilibrium constant of the Langmuir model, and qmax is the maximum amount of dye adsorbed on the adsorbent $(\mathrm{mg} / \mathrm{g})$. The values of qmax, $\mathrm{K}_{\mathrm{L}}$, and $\mathrm{R}^{2}$ are grouped in Table 8.

The Freundlich model assumes that the surface is heterogeneous with a non-uniform distribution of the adsorption's heat on the adsorbent surface and that there is multilayer formation on the surface [34]. The different parameters were obtained from the plot of $\log \left(\mathrm{q}_{\mathrm{e}}\right)$ versus $\log \left(\mathrm{C}_{\mathrm{e}}\right)$ to have a linear curve with a slope of $(1 / \mathrm{n})$ and the intercept of $\log \left(\mathrm{K}_{\mathrm{f}}\right)$. The values of the parameters $K_{f}, n$, and $R^{2}$ of the system's different states are presented in Table 8 . Comparing the values of the regression coefficients of the two isotherms for BB41 and SAF in the binary and the simple system shows that the Langmuir isotherm describes the equilibrium data well and shows that the adsorption is monolayer, with an $\mathrm{R}^{2}$ higher than 0.99 . $\mathrm{R}_{\mathrm{L}}$ values show that adsorption is favorable with a $0<\mathrm{R}_{\mathrm{L}}<1$.

Table 8. Isotherm data for BB41 and SAF in single and binary systems.

\begin{tabular}{|c|c|c|c|c|c|c|}
\hline & \multicolumn{3}{|c|}{ Langmuir } & \multicolumn{3}{|c|}{ Freundlich } \\
\hline System & $\mathrm{q}_{\mathrm{m}}$ & $\mathrm{K}_{\mathrm{L}}$ & $\mathrm{R}^{2}$ & $\mathrm{n}$ & $\mathrm{K}_{\mathrm{f}}$ & $\mathrm{R}^{2}$ \\
\hline BB41 (S) & 128.2 & 0.134 & 0.991 & 1.51 & 20.78 & 0.945 \\
\hline BB41 (B) & 75.18 & 0.231 & 0.996 & 1.94 & 16.27 & 0.984 \\
\hline SAF (S) & 111.11 & 0.163 & 0.998 & 1.65 & 17.32 & 0.979 \\
\hline SAF (B) & 80.64 & 0.154 & 0.995 & 1.72 & 12.92 & 0.988 \\
\hline
\end{tabular}

\section{Conclusions}

In this study, a PBD was used to select the factors influencing the adsorption of the mixture of two cationic dyes, BB41 and SAF, with 5 factors to study, such as the initial concentration of dyes, the mass of adsorbent (BBP), $\mathrm{pH}$ and temperature $\left({ }^{\circ} \mathrm{C}\right)$. A Pareto test selected the $\mathrm{pH}$ and adsorbent mass as factors that may significantly affect responses. A CCD was later used to optimize the factors responsible for the variation of removal efficiency, the analysis established two quadratic mathematical models of the BB41 and SAF, and the response surface shows the interactions of the $\mathrm{pH}$ factor and adsorbent mass and their effect on responses with a remarkable effect of BBP mass. The binary system's common optimal conditions were found to be a BBP dose of $0.46 \mathrm{~g} / 1$ and a $\mathrm{pH}$ of 8.54. Under the optimal conditions of the factors to be investigated, the dyes BB41 and SAF have a removal efficiency equal to 83.76 and $73.23 \%$, respectively, confirmed by an ulterior experiment under the same optimal conditions.

\section{Funding}

This research received no external funding.

\section{Acknowledgments}

The authors are grateful who have participated in this research work.

\section{Conflicts of Interest}

The authors declare no conflict of interest. 


\section{References}

1. Lu, L.; Li, J.; Yang, Song, P.; Zuo, M. Synthesis of novel hierarchically porous $\mathrm{Fe}_{3} \mathrm{O}_{4} @ \mathrm{MgAl}-\mathrm{LDH}$ magnetic microspheres and its superb adsorption properties of dye from water. J. Ind. Eng. Chem. 2017, 46, 315-323, https://doi.org/10.1016/j.jiec.2016.10.045.

2. Yagub, M.T.; Yagub, Sen, T.K.; Afroze, S. Ang, H.M. Dye and its removal from aqueous solution by adsorption: A review. Adv. Colloid Interface Sci. 2014, 209, 172-184, https://doi.org/10.1016/j.cis.2014.04.002.

3. Anuar, F.I.; Hadibarata, T.; Syafrudin, M.; Fona, Z. Removal of Procion Red MX- 5B from aqueous solution by adsorption on Parkia speciosa (stink bean) peel powder. Biointerface Res. Appl. Chem. 2020, 10, 47744779, https://doi.org/10.33263/BRIAC101.774779.

4. Abdulhameed, A.S.; Mohammad, A.T.; Jawad, A.H. Modeling and mechanism of reactive orange 16 dye adsorption by chitosan-glyoxal/TiO2 nanocomposite: application of response surface methodology. Desalin. Water Treat. 2019, 164, 346-360, https://doi.org/10.5004/dwt.2019.24384.

5. Barka, N.K.; Ouzaouit, K.; Abdennouri, M.; El Makhfouk, M. Dried prickly pear cactus (Opuntia ficus indica) cladodes as a low-cost and eco-friendly biosorbent for dyes removal from aqueous solutions. $J$. Taiwan Inst. Chem. Eng. 2013, 44, 52-60, https://doi.org/10.1016/j.jtice.2012.09.007.

6. Kumari, H.J.; Krishnamoorthy, P.; Arumugam, T.K. Radhakrishnan, S. Vasudevan, D. An efficient removal of crystal violet dye from waste water by adsorption onto TLAC/Chitosan composite: A novel low cost adsorbent. Int. J. Biol. Macromol. 2017, 96, 324-333, https://doi.org/10.1016/j.ijbiomac.2016.11.077.

7. Regti, A.; Laamari, M. R.; Stiriba, S.D. El Haddad, M. Potential use of activated carbon derived from Persea species under alkaline conditions for removing cationic dye from wastewaters. J. Assoc. Arab Univ. Basic Appl. Sci. 2017, 24, 10-18, https://doi.org/10.1016/j.jaubas.2017.01.003.

8. Kristanti, R.A.; Hadibarata, T.; Al Qahtani, H.M.S. Adsorption of bisphenol A on oil palm biomass activated carbon: characterization, isotherm, kinetic and thermodynamic studies. Biointerface Res. Appl. Chem. 2019, 9, 4217-4224, https://doi.org/10.33263/BRIAC95.217224.

9. El Haddad, M.; Regti, A.; Laamari, M.R.; Slimani, R.; Mamouni, R.; El Antri, S.; Lazar, S. Calcined mussel shells as a new and eco- friendly biosorbent to remove textile dyes from aqueous solutions. J. Taiwan Inst. Chem. Eng. 2014, 45, 533-540, https://doi.org/10.1016/j.jtice.2013.05.002.

10. Deniz, F.; Karaman, S.; Removal of Basic Red 46 dye from aqueous solution by pine tree leaves. Chem. Eng. J. 2011, 170, 67-74, https://doi.org/10.1016/j.cej.2011.03.029.

11. Regti, A.; El Ayouchia, H. B.; Laamari, M. R.; Stiriba, S.D.; Anane, H.; El Haddad, M. Experimental and theoretical study using DFT method for the competitive adsorption of two cationic dyes from wastewaters. Appl. Surf. Sci. 2016, 390, 311-319, https://doi.org/10.1016/j.apsusc.2016.08.059.

12. Bahloul, L.; Ismail, F.; Samar, M.E.H.; Meradi, H. Removal of AY99 from an aqueous solution using an emulsified liquid membrane. Application of Plackett-Burman Design. Energy Procedia. 2014, 50, 10081016, https://doi.org/10.1016/j.egypro.2014.06.120.

13. Thirugnanasambandham, K.; Sivakumar, V. An eco-friendly approach for copper (II) ion adsorption onto cotton seed cake and its characterization: Simulation and validation. J. Taiwan Inst. Chem. Eng. 2015, 50, 198-204, https://doi.org/10.1016/j.jtice.2014.12.002.

14. El Kassimi, A.; Achour, Y.; El Himri, M.; Laamari, M.R.; El Haddad, M. Process Optimization of High Surface Area Activated Carbon Prepared from Cucumis Melo by $\mathrm{H}_{3} \mathrm{PO}_{4}$ Activation for the Removal of Cationic and Anionic Dyes Using Full Factorial Design. Biointerface Res. Appl. Chem. 2021, 11, 1266212679, https://doi.org/10.33263/BRIAC115.1266212679.

15. El Kassimi, A.; Achour, Y.; El Himri, M.; Laamari, M.R.; El Haddad, M. Optimization of preparation conditions of highly efficient activated carbon for use in water treatment-experimental design approach. Int. J. Environ. Anal. Chem 2021, 1-23, https://doi.org/10.1080/03067319.2020.1861261.

16. Achour, Y.; Bahsis, L.; Ablouh, E. H.; Yazid, H.; Laamari, M. R.; El Haddad, M., Insight into adsorption mechanism of Congo red dye onto Bombax Buonopozense bark Activated-carbon using Central composite design and DFT studies. Surf. Interfaces. 2021, 23, 100977, https://doi.org/10.1016/j.surfin.2021.100977.

17. Al-Kadhi, N.S. The kinetic and thermodynamic study of the adsorption Lissamine Green B dye by microparticle of wild plants from aqueous solutions. Egypt. J. Aquat. Res. 2019, 45, 231238, https://doi.org/10.1016/j.ejar.2019.05.004.

18. Sharifpour, E.; Ghaedi, M.; Haddadi, H. Optimization of simultaneous ultrasound assisted toxic dyes adsorption conditions from single and multi-components using central composite design: Application of derivative spectrophotometry and evaluation of the kinetics and isotherms. Ultrason. Sonochem. 2016, 36, 236-245, https://doi.org/10.1016/j.ultsonch.2016.11.011.

19. Aly-Eldeen, M.A.; El-Sayed, A.A.M.; Salem, D.M.S.A.; El Zokm, G.M. The uptake of Eriochrome Black T dye from aqueous solutions utilizing waste activated sludge: Adsorption process optimization using factorial design. Egypt. J. Aquat. Res. 2018, 44, 179-186, https://doi.org/10.1016/j.ejar.2018.09.001. 
20. Regti, A.; El Kassimi, A.; Laamari, M.R.; El Haddad, M. Competitive adsorption and optimization of binary mixture of textile dyes: A factorial design analysis. J. Assoc. Arab Univ. Basic Appl. Sci. 2017, 24, 1-9, https://doi.org/10.1016/j.jaubas.2016.07.005.

21. Asfaram, A.; Ghaedi, M.; Hajati, S.; Goudarzi, A.; Dil, E.A. Screening and optimization of highly effective ultrasound-assisted simultaneous adsorption of cationic dyes onto Mn-doped Fe3O4-nanoparticle-loaded activated carbon. Ultrason.-Sonochemistry 2017, 34, 1-12, https://doi.org/10.1016/j.ultsonch.2016.05.011.

22. Dashamiri, S.; Ghaedi, M.; Asfaram, A.; Zare, Wang, F. S. Multi-response optimization of ultrasound assisted competitive adsorption of dyes onto $\mathrm{Cu}(\mathrm{OH}) 2$-nanoparticle loaded activated carbon: Central $\begin{array}{lllll}\text { composite } \quad \text { design. } & \text { Ultrason.-Sonochemistry }\end{array}$ https://doi.org/10.1016/j.ultsonch.2016.06.007.

23. Oyekanmi, A.A.; Ahmad, A.; Hossain, K.; Rafatullah, M. Adsorption of Rhodamine B dye from aqueous solution onto acid treated banana peel: Response surface methodology, kinetics and isotherm studies. PLoS One 2019, 14, https://doi.org/10.1371/journal.pone.0216878.

24. Asfaram, A.; Ghaedi, M.; Yousefi, F.; Dastkhoon, M. Experimental design and modeling of ultrasound assisted simultaneous adsorption of cationic dyes onto $\mathrm{ZnS}$ : Mn -NPs-AC from binary mixture. Ultrason. Sonochem. 2016, 33, 77-89, https://doi.org/10.1016/j.ultsonch.2016.04.016.

25. Saka, C.; Elçi Ölçenoğlu, G.; Şahin, Ö. Oxygen plasma treated petroleum coke adsorbent: characterization, synthesis, mechanism, and application for enhancement of malachite green removal. Int. J. Environ. Anal. Chem. 2021, 1-17, https://doi.org/10.1080/03067319.2021.1873305.

26. Pourabadeh, A.; Baharinikoo, L.; Nouri, A.; Mehdizadeh, B.; Shojaei, S. The optimisation of operating parameters of dye removal: application of designs of experiments. Int. J. Environ. Anal. Chem. 2019, 1-10, https://doi.org/10.1080/03067319.2019.1680657.

27. Behera, S.K.; Sahni, S.; Tiwari, G.; Rai, A.; Mahanty, B.; Vinati, A.; Pugazhendhi, A. Removal of chromium from synthetic wastewater using modified maghemite nanoparticles. Appl. Sci. 2020, 10, https://doi.org/10.3390/app10093181.

28. Parsaeian, M.R.; Dadfarnia, S.; Haji Shabani, A.M.; Hafezi Moghaddam, R. Green synthesis of a high capacity magnetic polymer nanocomposite sorbent based on the natural products for removal of Reactive Black 5. Int. J. Environ. Anal. Chem. 2020, 1-15, https://doi.org/10.1080/03067319.2020.1748612.

29. Gharbani, P. Modeling and Optimization of Reactive Yellow 145 Dye Removal Process onto Synthesized MnOX-CeO2 Using Response Surface Methodology. Colloids Surfaces A Physicochem. Eng. Asp. 2018, 548, 191-197, https://doi.org/10.1016/j.colsurfa.2018.03.046.

30. El Kassimi, A.; Regti, A.; Laamari, M.R.; El Haddad, M. Adsorptive removal of anionic dye from aqueous solutions using powdered and calcined vegetables wastes as low-cost adsorbent. Arab. J. Basic Appl. Sci. 2018, 25, 93-102, https://doi.org/10.1080/25765299.2018.1517861.

31. Harrou, A.; Gharibi, E.; Nasri, H.; El Ouahabi, M. Thermodynamics and kinetics of the removal of methylene blue from aqueous solution by raw kaolin. SN Appl. Sci. 2020, 2, https://doi.org/10.1007/s42452-020-2067y.

32. El Kassimi, A.; Achour, Y.; El Himri, M.; Laamari, R.; El Haddad, M. High Efficiency of Natural Safiot Clay to Remove Industrial Dyes from Aqueous Media: Kinetic, Isotherm Adsorption and Thermodynamic Studies. Biointerface Res. Appl. Chem. 2021, 11, 12717-12731, https://doi.org/10.33263/BRIAC115.1271712731.

33. El Kassimi, A.; Boutouil, A.; El Himri, M.; Rachid Laamari, M.; El Haddad, M. Selective and competitive removal of three basic dyes from single, binary and ternary systems in aqueous solutions: A combined experimental and theoretical study. J. Saudi Chem. Soc. 2020, 24, 527-544, https://doi.org/10.1016/j.jscs.2020.05.005.

34. Satlaoui, Y.; Nasraoui, R.; Charef, A.; Azouzi, R. Adsorption, Modeling, Thermodynamic, and Kinetic Studies of Methyl Red Removal from Textile-Polluted Water Using Natural and Purified Organic Matter Rich Clays as Low-Cost Adsorbent. J. Chem. 2020, 2020, https://doi.org/10.1155/2020/4376173. 